\title{
Groundwater pollution by longstanding cemetery and solutions for urban cemetery planning in Ho Chi Minh City - from reality to solutions
}

\author{
Trang Nguyen ${ }^{1, *}$ and Luan Nguyen $^{1}$ \\ ${ }^{1}$ Urban Engineering Department, Ho Chi Minh City University of Architecture, Vietnam
}

\begin{abstract}
The fast speed of urbanization in Vietnamese big city like Ho Chi Minh City (HCMC) has pushed a large number of longstanding cemeteries deep into the inner city. It consequently leads to the gradual loss of urban aesthetics and negative impacts on urban environment. Choosing location for cemetery in modernized city is currently realized as one of serious and difficult issues in terms of urban space planning. Also, it is an urgent concern of environmental problem. The result of traditional inhumation, for example, has led to an uncontrollable wide underground spread of polluted leachates exuding from human body corpses in longstanding cemetery and surrounding areas. In order to improve the effectiveness of urban planning, together with environmental and cemetery management and groundwater conservation responsibilities on site and surroundings of a cemetery, assessment of the groundwater pollution and simulation of the contaminant transport potential are compulsory. This study aims to conduct both tasks into Binh Hung Hoa (Tan Phu district) and Vinh Nghiem (district 12) cemeteries, the two typical longstanding cemeteries in HCMC.
\end{abstract}

\section{Introduction}

Cemetery (also called as graveyard or grave-field) is an essential component of urban infrastructure system. In Vietnam, cemetery is commonly established when a community of inhabitants is created and gathered. The total nationwide area of cemetery is enormous, but its distribution is inadequate and irrational, especially in large city like HCMC [1]. People seem to be familiar with the fact that longstanding and/or spontaneous grave-fields locate in the interior of the city. This is an inevitable corollary of the high-speed urbanization, together with fast increase in population and insufficient tight control of nonresident. Therefore, this corollary has put pressure on urbanwide socio-economics, infrastructure, environment, and healthcare assurance. It is obviously realized that a new planning or expanding of cemetery area complying with regional and local planning direction always challenges the local administrators. Inhabitants, on the other hand, seem to be unconcerned with actions regarding changes in cemetery location.

*Corresponding author: canxius@gmail.com 
Polluted groundwater on the site and surroundings of longstanding and spontaneous cemeteries has been considering as one of the most urgent concerns of people and society for many years. The pollution caused by biological decomposition process of a body corpse after a long time being buried into grave and leachates of ground-absorption process. The leachates may comprise embalming solutions, disease agents, bacteria, organic and inorganic decomposition compounds, such as: nitrogen and phosphorous compounds which are currently identified as serious groundwater contaminants. If people use polluted groundwater polluted by those agents as household water supply, then it may become a cause of local epidemic diseases [2]. There has no conclusive evidence to show the potential of spread of disease by leachates exuding from human body corpses in longstanding graveyard in HCMC. The potential, however, has been still dubious and concerned with high reliability due to the deficiency of scientific base.

Binh Hung Hoa cemetery, the largest cemetery of HCMC, was founded spontaneously in Tan Phu district with a total area of 44 hectares approximately in 1945. It was ceased to stop traditional burial activities in 2008. Although it has been connected with the city water supply system for recent years, people living in site and surroundings still keep their habits of exploiting groundwater for daily use. The reasons are listed as: (1) undisciplined management of city and official authority; (2) unsuitable and inefficient regulations; and (3) unwilling to pay for use. By that uncontrollable exploitation of groundwater, people have put their contribution to hasten the spreading of contaminants exuding from human body corpses.

Another concern in this study is Vinh Nghiem cemetery located in district 12 with a total area of 2.4 hectares approximately. It has a similar critical condition of pollution to Binh Hung Hoa cemetery. Vinh Nghiem cemetery was found spontaneously before 1975 and has still been running up to now. The practical observational results carried out since 2015 to 2017 and released by the Division for Water Resources Planning and Investigation for the South of Vietnam show that the concentration of the following contaminants: ammonium $\mathrm{NH}_{4}{ }^{+}$, nitrate $\mathrm{NO}_{3}{ }^{-}$, nitrite $\mathrm{NO}_{2}{ }^{-}$, chemical oxigen demand (COD), and heavy metal ions in groundwater samples have exceeded significantly in comparison with the Vietnam National Technical Regulation on Groundwater Quality QCVN 09:2015/BTNMT [3].

Groundwater pollution facts of the two above longstanding cemeteries, together with undisciplined planning management and inappropriate solutions for treatment, has demonstrated the urgent necessity to complement appropriate planning for new cemeteries and "green-expanding" for present ones.

\section{Materials and methods}

\subsection{Principles for the spread of contaminant}

Burial methods may vary due to the regional differences, habits and customs of countries or peoples, and religions. It consists of inauspicious burials, inhumation, and cremation. Other alternative but unpopular methods include water burials, burial to the sea, sky burials, stoneburials, etc. Each method has its own spirit meanings. In terms of groundwater pollution potential, however, inhumation and water burial are believed to be the two most serious methods with highest contaminants.

A coffin (also called as casket) is commonly buried at a depth of 1.8 meters from the topsoil. In some cases of specific planning, the minimum burial depth is 1.3 meters from the topsoil [4]. By inhumation of coffins or death body corpses directly into the ground, human has put their contribution to hasten the spreading rate of contaminants into the aquifers. If the local strata and sediment of geology, in particular, are sufficient for contaminants being permeated faster, in addition to other conditions (i.e. the minimum dilution capability, 
biological attenuation limitations, physical and chemical reactions and interstage progress limitations), then the spread of contaminants may increase more significantly. The quality of groundwater, therefore, would be menaced unpredictably [2]. The deeper the person is buried, the faster the spread.

Leachates exude from landfill human body corpses with a slow rate. The majority of landfill leachates will permeate through the soil, while the residual may be evaporated or dissipated into the air. Leachates initially begin its spread from the coffin in which a death body corpse is covered to the unsaturation zone. These post-absorption products in the unsaturation zone will be pushed to the saturation zone on a downward path and infect contaminants to the aquifers (see Figure 1).

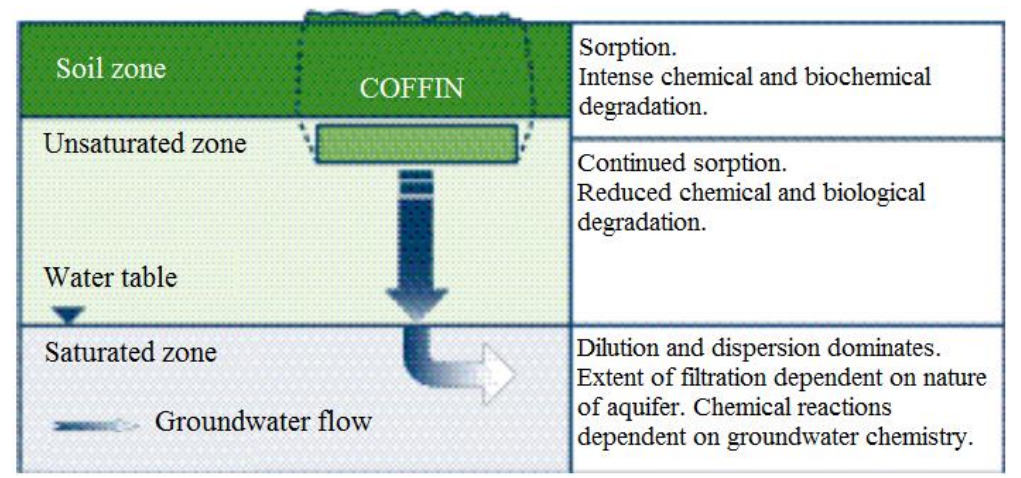

Fig. 1. Natural attenuation processes of leachates exuding from landfill human body corpses.

Diffusion and transport are the two most essential processes which control the speed and scale of contaminants spreading underground. Other factors which could affect directly to the spreading of contaminants are the dimension and porosity of soil. Contaminants (or polluted fluid flows) are transported through the soil interstices and redirect sequent to split off to smaller streams. It is called as a mechanic dispersion process, where small contaminant streams are being agitated by hydraulic pressure. This process, consequently, occurs to reduce the concentration of saluted contaminants. Also, it could be called as the dilution process of saluted contaminants, in other words.

Computing and balancing the interaction of soil, water and saluted contaminants are employed to simulate the three processes of solution, sedimentation, and adsorption; in which results obtained in the adsorption process computing are the most significant basis of the simulation model for contaminants transport in this study.

\subsection{Pollution facts of groundwater at longstanding cemeteries in Ho Chi Minh City}

Expanding urban land will eventually narrow the total area of cemeteries in city. It is currently being a serious concern of a megacity of Ho Chi Minh City as old-cemeteries are encircled with new constructions and residential areas. Habitants surrounding such longstanding cemeteries, therefore, are threatening with pollutions of water, soil, and other living conditions. Reference [5] has released numerous evidences which demonstrate potential of serious pollutions by longstanding cemeteries, especially in cases of losing tight management in planning foundations, and development.

In developing and undeveloped countries worldwide, most cemeteries are founded without sufficient concerns on the risks of pollution potentials by death body corpses [4]. According to [4], contaminants proceeding from old-cemeteries (also defined as leachates exuding from human body corpses) could infected on water, soil, and air surrounding its 
spaces; in which groundwater is the most important harm of all. Leachates exuding from human body corpses are disease contaminants which could infect seriously on groundwater and surface-water if the aquifers are too closed to the topsoil layer [5]. This threaten is more serious as: (1) spontaneous longstanding cemeteries were founded in adjacent to residence zones; (2) undisciplined management in planning and design; (3) lack of comprehension and analyses on site survey, locations, geological conditions, and other environmental factors; and (4) insufficient regulations on urban planning and construction management.

According to the results published in [4] and [6] on pollution potential of cemetery developments, most cases of pollution caused by human death body not only contaminate groundwater in the first year of burial but expand its pollution continuously in many years afterwards. It commonly takes 10 to 12 years for a human death body corpse being decomposed completely, approximately. Up to 50 percent of contaminants from a corpse will be exuded into the aquifer and soil in the first year and the remained half will be sent in later years [6] (see table 1). When groundwater is infected by biological contaminants produced in decomposition process, then human health and living conditions will be impacted seriously as a firm consequence.

Table 1. Concentration of contaminants $(\mathrm{kg})$ released from a human body corpse with a weight of $70 \mathrm{~kg}[6]$.

\begin{tabular}{|c|c|c|c|c|c|c|c|c|c|c|}
\hline Year & TOC & $\mathrm{NH}_{4}$ & $\mathrm{Ca}$ & $\mathrm{Mg}$ & $\mathrm{Na}$ & $\mathrm{K}$ & $\mathrm{P}$ & $\mathrm{SO}_{4}$ & $\mathrm{Cl}$ & $\mathrm{Fe}$ \\
\hline 1 & 6.00 & 0.87 & 0.56 & 0.010 & 0.050 & 0.070 & 0.250 & 0.210 & 0.048 & 0.020 \\
\hline 2 & 3.00 & 0.44 & 0.28 & 0.005 & 0.025 & 0.035 & 0.125 & 0.110 & 0.024 & 0.010 \\
\hline 3 & 1.50 & 0.22 & 0.14 & 0.003 & 0.013 & 0.018 & 0.063 & 0.054 & 0.012 & 0.005 \\
\hline 4 & 0.75 & 0.11 & 0.07 & 0.001 & 0.006 & 0.009 & 0.032 & 0.027 & 0.006 & 0.003 \\
\hline 5 & 0.37 & 0.05 & 0.03 & $<0.001$ & 0.003 & 0.004 & 0.016 & 0.012 & 0.003 & 0.001 \\
\hline 6 & 0.19 & 0.03 & 0.02 & $<0.001$ & 0.002 & 0.002 & 0.008 & 0.006 & 0.002 & $<0.001$ \\
\hline 7 & 0.10 & 0.01 & 0.01 & $<0.001$ & 0.001 & 0.001 & 0.004 & 0.003 & $<0.001$ & $<0.001$ \\
\hline 8 & 0.50 & $<0.01$ & $<0.01$ & $<0.001$ & $<0.001$ & $<0.001$ & 0.002 & 0.001 & $<0.001$ & $<0.001$ \\
\hline 9 & 0.02 & $<0.01$ & $<0.01$ & $<0.001$ & $<0.001$ & $<0.001$ & 0.001 & $<0.001$ & $<0.001$ & $<0.001$ \\
\hline 10 & 0.01 & $<0.01$ & $<0.01$ & $<0.001$ & $<0.001$ & $<0.001$ & $<0.001$ & $<0.001$ & $<0.001$ & $<0.001$ \\
\hline
\end{tabular}

Note: TOC - Total Organic Carbon.

Binh Hung Hoa cemetery located in Tan Phu district has an estimated 94,000 graves in total and approximately 300,000 residents living among the tombs [3] (see figure 2). Burials were ceased in this cemetery since 2011 as it was decided to be relocated by the city authorities in 2008. In terms of environmental and groundwater pollutions, there is something dubious and concerned to be studied further.

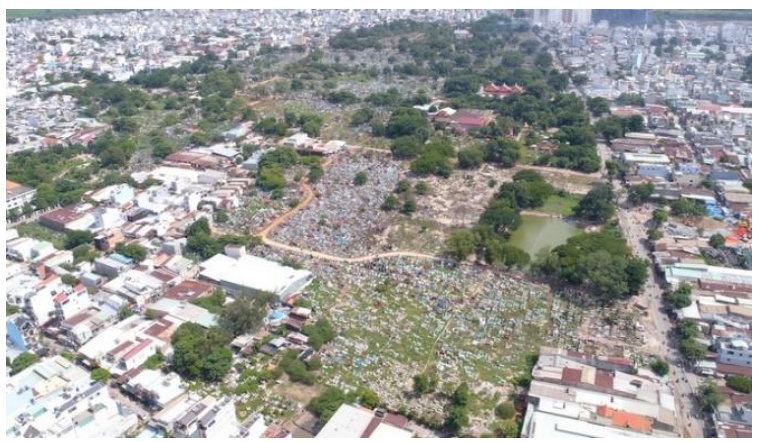

Fig. 2. Overview of Binh Hung Hoa cemetery.

Having similar conditions with Binh Hung Hoa cemetery, Vinh Nghiem cemetery was founded spontaneously by 1975 . It was encircled closely with residential areas surrounding its space. This 42-years old cemetery has been accommodated 2,200 bodies during its lifetime. Although it has a much smaller size than Binh Hung Hoa cemetery, there is no doubt that pollution is currently uncontrollable with dozens of complicated symptoms, similarly. Numerous observational surveys were carried out by the Division for Water Resources 
Planning and Investigation for the South of Vietnam during 2015-2017 period to analyze the physical and chemical characteristics of groundwater, surface-water and soil surrounding the two cemeteries. Results show that the concentration of following contaminants: amonium $\mathrm{NH} 4+$, nitrate NO3-, nitrite NO2-, chemical oxigen demand (COD) and heavy metal ions in groundwater samples have exceeded significantly in comparison with the National Technical Regulation on Groundwater Quality QCVN 09:2015/BTNMT [3]. The quality parameters of soil surrounding Binh Hung Hoa and Vinh Nghiem cemeteries are shown in table 2, table 3, table 4 , and table 5 as below:

Table 2. Percentage of contaminants exceeded the Vietnam National Technical Codes in groundwater samples collected from inner-site of Binh Hung Hoa and Vinh Nghiem cemeteries in Aug $\div$ Nov 2016 and Apr 2017.

\begin{tabular}{|c|c|c|c|c|c|c|c|c|c|}
\hline \multirow{4}{*}{ Parameters } & \multirow{4}{*}{$\begin{array}{l}\text { Restriction } \\
\text { according } \\
\text { to (1) }\end{array}$} & \multicolumn{8}{|c|}{ Percentage of contaminants exceeded the restriction in groundwater samples } \\
\hline & & \multicolumn{4}{|c|}{ From August to November 2016} & \multicolumn{4}{|c|}{ April 2017} \\
\hline & & \multicolumn{2}{|c|}{ Vinh Nghiem } & \multicolumn{2}{|c|}{ Binh Hung Hoa } & \multicolumn{2}{|c|}{ Vinh Nghiem } & \multicolumn{2}{|c|}{$\begin{array}{c}\text { Binh Hung } \\
\text { Hoa }\end{array}$} \\
\hline & & qp3 & qp2-3 & qp3 & qp2-3 & qp3 & qp2-3 & qp3 & $\begin{array}{c}\mathrm{qp} 2- \\
3\end{array}$ \\
\hline $\mathrm{NH}_{4}^{+}$ & 1 & 50 & 0 & 50 & 0 & 50 & 0 & 100 & 0 \\
\hline $\mathrm{NO}_{3}^{-}$ & 15 & 50 & 0 & 0 & 0 & 0 & 0 & 0 & 0 \\
\hline $\mathrm{Fe}^{2+}$ & 5 & 0 & 0 & 50 & 0 & 0 & 0 & 50 & 0 \\
\hline COD & 4 & 0 & 0 & 50 & 50 & 0 & 0 & 0 & 0 \\
\hline $\mathrm{Cd}$ & 0.005 & \multicolumn{3}{|c|}{ GHCP } & 50 & \multicolumn{4}{|c|}{ KPH } \\
\hline Phenol & 0.001 & \multicolumn{4}{|c|}{ KPH } & 100 & 50 & 50 & $\mathrm{KPH}$ \\
\hline
\end{tabular}

Note: (1) is the Vietnam National Technical Regulation on Groundwater Quality QCVN 09:2015/BTNMT; Unit of quality parameters: $\mathrm{mg} / \mathrm{l}$; qp3, qp2-3: the upper pleistocene and the intermediate pleistocene layer, respectively; GHCP: certain values stipulated in (1) - restriction; KPH - unidentified.

Table 3. Percentage of contaminants exceeded the Vietnam National Technical Codes in groundwater samples collected from surrounding area of Binh Hung Hoa and Vinh Nghiem cemeteries in October and November 2015.

\begin{tabular}{|c|c|c|c|c|c|c|}
\hline \multirow{3}{*}{ Parameters } & \multirow{3}{*}{$\begin{array}{l}\text { Restriction } \\
\text { according to } \\
\text { (1) }\end{array}$} & \multicolumn{5}{|c|}{ Percentage of contaminants exceeded the restriction in groundwater samples } \\
\hline & & \multicolumn{3}{|c|}{ Vinh Nghiem } & \multicolumn{2}{|c|}{ Binh Hung Hoa } \\
\hline & & qp3 & qp2-3 & qp1 & qp3 & qp2-3 \\
\hline $\mathrm{NH}_{4}^{+}$ & 1 & 29 & 33 & 0 & 20 & 15 \\
\hline $\mathrm{NO}_{3}{ }^{-}$ & 15 & \multicolumn{3}{|c|}{0} & 60 & 29 \\
\hline COD & 4 & 86 & 100 & 50 & 100 & 29 \\
\hline $\mathrm{Cd}$ & 0.005 & 15 & \multicolumn{2}{|c|}{ GHCP } & 20 & GHCP \\
\hline Phenol & 0.001 & 57 & \multicolumn{2}{|c|}{100} & 40 & 15 \\
\hline $\mathrm{Hg}$ & 0.001 & \multicolumn{3}{|c|}{$\mathrm{KPH}$} & 80 & 43 \\
\hline $\mathrm{CN}$ & 0.01 & 15 & $\mathrm{KPH}$ & GHCP & \multicolumn{2}{|c|}{$\mathrm{KPH}$} \\
\hline
\end{tabular}

Note: qp1 - the lower pleistocene.

Table 4. Percentage of contaminants exceeded the Vitenam National Technical Codes in surface-water samples collected from surrounding area of Binh Hung Hoa and Vinh Nghiem cemeteries in October and November 2015.

\begin{tabular}{|c|c|c|c|}
\hline \multirow{2}{*}{ Parameters } & \multirow{2}{*}{ Restriction according to (2) } & \multicolumn{2}{|c|}{$\begin{array}{c}\text { Percentage of contaminants exceeded the restriction in } \\
\text { surface-water samples }\end{array}$} \\
\cline { 3 - 4 } & & Vinh Nghiem & Binh Hung Hoa \\
\hline $\mathrm{NH}_{4}{ }^{+}$ & 0.9 & 75 & 50 \\
\hline $\mathrm{NO}_{2}^{-}$ & 0.05 & $\mathrm{GHCP}$ & 75 \\
\hline $\mathrm{COD}$ & 50 & 50 & 75 \\
\hline $\mathrm{PO} 4^{3-}$ & 0.5 & 75 & 50 \\
\hline $\mathrm{Cd}$ & 0.01 & $\mathrm{KPH}$ & 50 \\
\hline $\mathrm{Hg}$ & 0.002 & $\mathrm{KPH}$ & 25 \\
\hline
\end{tabular}

Note: (2) - is the National Technical Regulation on Surface-water Quality QCVN 08:2015/BTNMT column B2; Unit of quality parameters: $\mathrm{mg} / \mathrm{l}$. 
From component-analysis results on ground- and surface-water quality, as well as quality of soil collected at burial and surrounding areas of Vinh Nghiem and Binh Hung Hoa cemetery, it is obviously that: (1) there are appearances of amonium $\mathrm{NH}_{4}^{+}$and COD pollutions at the upper pleistocene layer of Vinh Nghiem cemetery and at both upper and intermediate pleistocene layers of Binh Hung Hoa cemetery; and (2) amonium $\mathrm{NH}_{4}^{+}$, phosphate, and COD pollutions and heavy metal ions are found in ground- and surface-water samples collected surrounding the two graveyard areas..

According to the statistics of the HCMC Department of Natural Resources and Environment, there are an estimated 9,300 cemeteries located around the city with a total land area of approximately 1,200 hectares, in which only 100 hectares is gathered as municipal graveyard; remaining 1,100 hectares scattered in inner-residential areas around the city are the total land area of spontaneously cemeteries [7]. In particular, the total land area of cemeteries in Hoc Mon district is around 180 hectares with the majority being accounted for spontaneous founded cemeteries and longstanding graveyards. Hoc Mon, located in the suburban outskirts of the city, have not been supplied with an accomplished pure-water supply system for entire district. Residents living in Hoc Mon district are still exploiting water from drilled-wells (or boreholes) for diurnal uses without worrying about contaminations. Similarly, district 12 is highlighted by 100 small graveyards with a total land area of approximately 50 hectares. Binh Chanh district is remarkable with tombs located spontaneously alongside the traffic and inter-village roads [7]. There are no conclusive studies to demonstrate the risks of pollution caused by contaminants exuding from oldgraveyards in a large city like HCMC. However, it is believed that human health and lifespan of people living around longstanding cemeteries has been affected considerably.

\subsection{Reality of planning activities for cemetery in Ho Chi Minh City}

Demand for burial space is increasing significantly regarding both quality and quantity. Therefore, demand-forecasting plays an essential role to release planning orientation for the land-use of every region. A demand prediction model is commonly based on the rate of deaths, population and forecasted increase rate of population of a region or city [8]. Statistics published by the HCMC Department of Planning and Architecture in 2014 shown that: (1) HCMC population is predicted to reach approximately 20 billion by 2020 ; (2) the death rate is estimated at 40,000 people/year (equivalent to 0.4 percent), of which 8,000 people will be buried at their hometown, while others 32,000 burials will be carried out in HCMC, suburban areas and adjacent provinces [9]. By a 15-square-meter plot as burial standard, HCMC alone have to expand 40 hectares of cemetery space per year to accommodate its annual dead.

Unfortunately, results from practical planning have shown an opposite evidence that separate predicted estimations based on regional death rate could not be employed to forecast the future demand of burial plots in the next 10, 20, or 100 years afterwards. Alternatively, other factors could directly impact on burial demand comprise resettlement, inter-migration, burial methods, etc. As a consequence, it is perplexed for planners and governmental authorities to make a decision on planning land-use for urban cemetery. Reforming oldcemetery or constructing a new one to accommodate the increasing burial demand has been confusing the city administrator for recent years. Also, choosing location for new cemeteries has been a serious matter of controversy.

According to the Decree 23/2016/ND-CP on Construction, Management, and Employment of Cemeteries and Burial Land, planning of provincial cemetery system is defined as gathering and organizing activities of graveyards, burial lands, and funeral houses distributed separately in inner provincial official boundaries to comply with the provincial master plan, provincial land-use plan, and local plan for socio-economic development [10]. All cemeteries (include both operating and ceased cemeteries) must be maintained 
periodically. The environmental conditions of cemeteries must be controlled under stipulated regulations. An updated Decree [10] revised on the basis of the Decree 35/2008/ND-CP has been released and come into effect for 10 years but it seems to be insufficient regarding regulations on cemetery and burial facilities planning [1]. For this reason, "burial land fever" has been occurred in many provinces and big cities of Vietnam, especially in HCMC.

Recently, the cost of a burial land-plot has increased significantly due to the explosion of traditional burial demand. It leads to a foundation of burial land trading market being effervescent. Particularly, people living in rural areas and suburban outskirts of the city are willing to sell their lands to anybody who has demand of burial. There is no legal tariff frame for burial land. It totally depends on agreement between buyers and the land-owners. Thus, the tariff may vary significantly from region to region. As a result, it is arduous for local authorities to monitor the operation of spontaneous cemeteries.

Recently, Vietnam Government has released numerous national subsidies to promote the burial land trading market. Business enterprises are currently being encouraged to invest in this market according to The Decree 23/2016/ND-CP. It means that the burial land trading has been recognized as a business service term [10]. Accordingly, business enterprises who invest in commercial cemeteries will be subsidized with various ways, i.e: free of land-use taxes, infrastructure free use, sharing a partial or full of compensation allowance for site clearance based on project-scales and types of investment. Moreover, commercial burial investment is not only a non-tax enterprise but also known as a revenue-undeclared business. Buying and selling burial land plots are totally flexible related to amount of plot, unlimited right to change owners and other concessions. For these reasons, this type of trading is believed as the most eventful segment of business services, while the luxury-property and residential house segment are reducing its attraction. In general, commercial cemetery segment is a sensitive but super profit enterprise. That is the reason why many investors are willing to spend their money on it.

Old cemetery clearance and reallocation, on the contrary, has been decompressed for decades. For example, the People's Committee of HCMC has released a decision for ceasing operation of Binh Hung Hoa cemetery in 2008. Then, Binh Hung Hoa reallocation project was listed in the Master Plan for Socio-Economic Development in HCMC through 2020, towards 2025, which was then approved by the Prime Minister Nguyen Tan Dung in 2013. Accordingly, the estimated capital cost of project is 2,500 billion Vietnam Dong.44 hectares of cemetery is planned to be cleared, of which 24 hectares will be redesigned as green and public space; 12 hectares is necessary to construct new commercial buildings, while remaining 8 hectares is deployed for complex-functional purposes by 2020 . However, up to July 2017, about 4,000 tombs have not been exhumed and moved yet. It means that the first phase of Binh Hung Hoa clearance project will not be on schedule (the estimated term is end of December 2017). The second phase of project will be deployed to prepare 11.54 hectares of site clearance and 22,000 graves reallocation (the estimated start will be early November 2017). Slow clearance, insufficient compensation allowance and unwilling agreement of habitants who have family resting there have been determined as the three most significant obstacles. They are preventing the cemetery transformation project to be finished on time. In order to extricate those issues, the People's Committee of Binh Tan district has offered a proposal to bid cleared areas to attract investors. This suggestion once being approved and come into effect may share with the city by regenerating finance for further clearance phases.

Although covering a longstanding cemetery with trees and creating open public spaces could be an effective greening solution to improve the landscape, aesthetics and filtering the air, groundwater pollution could not be resolved. Does investor willing to pay for pollution treatments before building new constructions? Or clearing cemetery also means as ignoring pollution? These questions have not been answered yet. Therefore, it is compulsory and urgent for the city authorities to find convincing solutions before approving new plans on a 
longstanding cemetery. Other departments and institutes, certainly, must be responsible for co-operating with the city authorities in protecting environment. Potential investors, additionally, must share responsibilities with the city and residents to preserve groundwater sources besides aiming to get profit only.

\section{Discussion}

According to Vietnam regulations, cemetery planning is a component of: (1) master plan for land-use; (2) regional construction plan; (3) master plan for urban constructions; and (4) master plan for rural residential zone [10]. Thus, cemetery planning process must comply with high-level planning requirements. As published in [1], a cemetery planning is a sevenstep process:

Step 1: Define boundaries, do site surveys and release site assessments;

Step 2: Classify types of funeral, scale and land-use parameters;

Step 3: Planning for land-use and landscape;

Step 4: Planning for infrastructure system;

Step 5: Strategic environment assessment or Environmental impact assessment;

Step 6: Counsel communities and local authorities;

Step 7: Prepare document for approval and appraisal.

Other regulations referred to planning process include: Vietnam National Code TCVN 7956:2008 on Urban Cemetery Design Standards, National Technical Regulation QCVN 0710:2016/BXD on Technical Infrastructure Works - Cemetery, Vietnam Building Code QCXDVN 01:2008/BXD on Regional and Urban Planning and Rural Residential Planning, and Vietnam Building Code QCXDVN 14:2009/BXD on Rural Residential Planning.

National building regulations and infrastructure system in co-operation with burial facilities are once conducted to master, regional and provincial plans may lead to space regeneration related to appearance and aesthetics. Unfortunately, Vietnam infrastructure systems are extremely overloaded and cannot meet the rapid increasing demand of transportation and residential settlement. For this reason, employing clearance for city inner longstanding cemeteries to mitigate contaminant conductivity into groundwater is compulsory. Other solutions could be implemented in lines with cemetery clearance include: on-site chemical-based treatments, utilizing land-use planning, green-cemetery deployment and cemetery park.

Cemetery park has been deployed in commercial-scale for decades. However, it is a brand-new concept of Vietnam. A cemetery park, which comprises a large proportion of trees, reservoirs, walkways, scrubs and decorative graves, is considered as a sustainable solution. In other words, a cemetery park will be integrated with Feng-shui objects to retrieve natural final resting places for deaths. Being an Eastern cultural country, Vietnamese spirit life is significantly influenced by fengshui, which comprises elements of geology, astrology, psychology, physics, intuition, astronomy and mathematics. People believe that traditional inhumation together with appropriate feng-shui elements could bring peace to the deaths, whose souls will stay and protect their descendants forever. According to the feng-shui, a supernatural energy could be formed when a dead human is buried at his right locations. This energy will be covered and protect to the whole family. Therefore, people are willing to pay lots of money to get a suitable grave location for their ancestors. Cemetery park investors, for this reason, put their great efforts to build facilities which could satisfy all in-need demands of burial customers. Types of grave could vary due to architectural design, family demands, religious and funeral style differences, i.e. single tombs, double tombs, semitombs, religious tombs, ash-urns, cremation zones, etc. One thing should be considered that a cemetery park does not allow graves of inauspicious burials but bone-ashes, cremation ashes, and exhumed ashes only. A high density polyethylene (HDPE) closed plates system 
and a leachate-collection system are used and put at the outer bottom of tombs to prevent leachates being conducted to groundwater and deeper aquifers (see Figure 2).

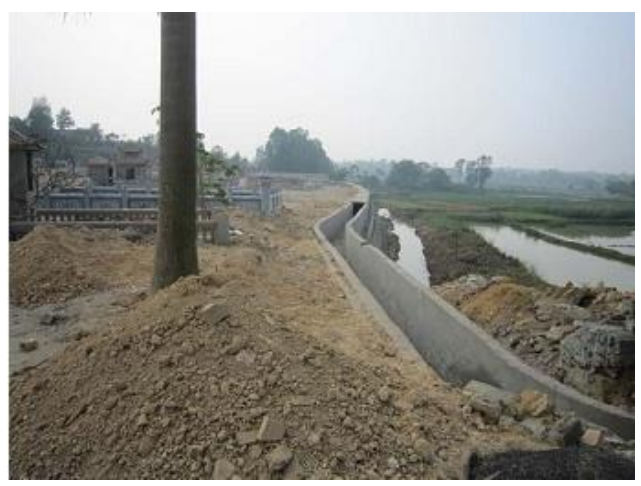

Fig. 3. Sewage Disposal System in Vinh Hang Cemetery.

Another updated concept to Vietnam is green-grave (or green burial). In traditional burial method, a death body corpse is placed into a decomposed-durable wooden coffin (hardwood, timber hardboards), which will be filled with additional smell and leachate-absorptions (coffee powder, dried flavorings, tea-leaves) as mummifying substances afterwards. Metallic coffin could be rarely used with formaldehyde-based mummification method. Formaldehyde is an extremely toxic chemical substance. It has been strictly forbidden in many European countries for mummification. Green inhumation, in contrary, is recommended to be implemented in Vietnam by environmental conservationists. It has a similar burial method with traditional way as a death body corpse will also be placed into a coffin and buried into the ground. However, easily decomposed woods will be used as alternative materials, while metallic and decomposed-durable materials are prohibited. The burial depth, additionally, will be reduced to mitigate conductivity potentials of contaminants into the aquifers (see figure 3). Burial cost, also, could be decreased by thinner removal of topsoil and cheaper materials.

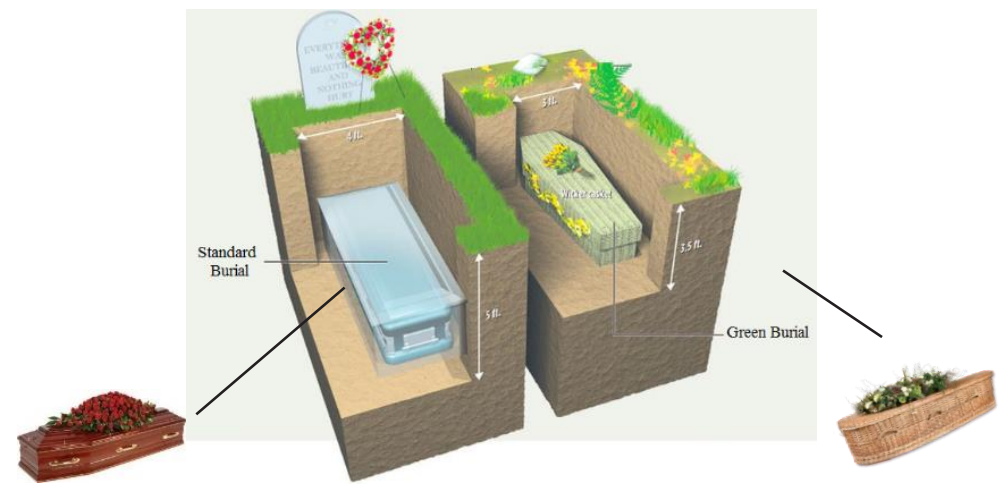

Fig. 4. Differences of traditional burial and green burial methods.

Besides green inhumation, numerous contamination treatment approaches have been implemented for landfills including burial cemetery.

Point source contamination treatment method is a general way in which polluted groundwater is disinfected in the aquifers. It consists of soil vapor extraction (SVE), air sparging, bioremediation, chemical treatment, dual-phase extraction, in-well air stripping, Permeable Reactive Barriers (PRB), and Phyto-remediation. 
Employing the aquifers as a "pollution treatment station", contaminants conductivity could be controlled in terms of transport-mitigation. When point-source pollution treatment methods are sufficiently concerned and implemented in cemetery construction planning, then the city aesthetics and its new cemeteries will be improved significantly related to green clean - beautiful terms.

\section{Conclusions}

Groundwater pollution facts of the two longstanding cemeteries as Binh Hung Hoa and Vinh Nghiem have demonstrated another fact that although planning for cemetery land-use in HCMC has been oriented regarding purposes and scale, but none for interprovincial interactio. Regulations related to construction, management, cemetery and funeral exploitation have been released for recent years, but their validity is too weak to be come into effect appropriately. As the city has been accepted existing longstanding cemeteries since the day they were founded, and willing to approve for new cemetery park projects of private enterprises, the number of city-interior cemetery is still high. As a consequence, land-use utilization, groundwater treatment, and environmental conservation are still remained. Therefore, various recommendations involved in cemetery planning and management were listed below as efficient solutions for the city:

- Fulfill the national regulations on cemetery investment, construction, management and planning. However, a fulfilled regulation must be strict enough to become national legalbase of cemetery-related works. Also, it must be reasonably flexible to keep specific characteristics of regions, religions, and ethnics;

- Prepare a site-map of cemetery land-use as practical base for further studies and planning on interprovincial cemeteries and funeral land-use utilization;

- Improve tools for cemetery land-use monitoring and management skills for official staffs;

- Establish general and specific strategies for regulation implementation on cemetery investment, construction, management, and planning;

- Set appropriate tariffs for basic funeral services to avoid uncontrollable collections;

- Cease operation of overload cemeteries;

- Set the optimal and minimal size for a grave-plot and a cemetery, apply it as a legal-base for clearing and relocating longstanding cemeteries;

- Improve official procedure on land-delivery in general and funeral land delivery in specific;

- Figure-out solutions for hastening site-clearance and land-collection projects to prepare for new cemetery construction projects;

- Employ financial instruments (i.e. tax instruments) to balance and monitor the cemetery land trading market.

- Promote mobilizing programs to gain community awareness and orient people towards green and new funeral methods;

- Deploy point source contamination treatment methods to longstanding cemeteries and cemetery park to mitigate contaminants conductivity into the aquifers.

\section{References}

1. Luu Duc Cuong, Study on compiling Proposal Strategy for Cemetery and Burial Management in Urban and Rural Residential Areas of Vietnam through 2020 (Vietnam Institute for Urban and Rural Planning, 2016) 
2. C.P. Young, K.M. Blackmore, P.J. Reynolds, A. Leavens, Pollution Potential of Cemeteries - Draft Guidance, R\&D Techinical Report P223, ISBN 1857050215 (Environment Agency for England and Wales, 1999)

3. Division for Water Resources Planning and Investigation for the South of Vietnam Survey Reports on HCMC Burial Facilities, a task of Ministrial Research Project: Groundwater Conservation for Ho Chi Minh City (2017)

4. Environment Agency for England and Wales, Assesing the Groundwater Pollution potential of Cemetery Developments, National Groundwater and Contaminated Land Centre (Solihull, Booklet, 2004)

5. A. Tumagole, A. Keneilwe, Geochemical Survey of Underground Water Pollution at Ditengteng Northern Cemetery Within City of Tshwane Municipality, MSc Thesis (The University of Johannesburg, South Africa, 2005)

6. F.W.J. Van Haaren, Cemeteries as Sources of Groundwater Contamination 35(16), 167172 (1951)

7. Ho Chi Minh City Department of Natural Resources and Environment, Announcement No. 742/TB-VP (2013)

8. V. Capels, W. Senville, Planning Commissioners Journal, 64 (2006)

9. Ho Chi Minh City Department of Planning and Architecture, Master Plan for Regional Construction in Ho Chi Minh City through 2030, perspective to 2050, according to the Decision No. 1065/QD-TTg (2014)

10. The Prime Minister, Decree 23/2016/ND-CP on Construction, Management, and Employment of Cemeteries and Burial Land (2016)

11. B.B. Dent, M.J. Knight, Cemeteries: A Special Kind of Landfill. The Context of Their Sustainable Development, Groundwater: Sustainable Solutions Conference (Melbourne, IAH, 1998)

12. C.P. Young, K.M. Blackmore, P.J. Reynolds, A. Leavens, Pollution Potential of Cemeteries - Draft Guidance, in R \& D Techinical Report P223, ISBN 1857050215 (Environment Agency for England and Wales, 1999)

13. A. Hart, S. Casper, Potential Groundwater Pollutants from Cemeteries, ISBN 1844323471 (Environment Agency, 2004)

14. C.W. Fetter, Contaminant Hydrogeology (Macmillan Publishing Company, New York, 1992) 